\title{
correspondence
}

\section{Catastrophe theory reply}

SIR,-This is a reply to a number of recent letters (Nature 270, 381-384 and 658 ; 1977) attacking our article (Zahler \& Sussmann Nature 269, 759; 1977) on applied catastrophe theory. Many of these cite applications in the physical sciences to rebut our criticism; but as we were careful to state repeatedly in our paper, our discussion applied only to models in the biological and social sciences. In a more specific complaint, the respected mathematician John Guckenheimer asserts that we ignored recent work of Kozak and Benham on denaturation (Benham \& Kozak J. Theor. Bio. 63, 125; 1976), where the Maxwell convention, not the delay rule, is used. The effect of this change, however, is to remove the cusp, and thus the catastrophe theory, from the analysis. Dodson's letter gives another reason why catastrophe theory should not apply to denaturation.

A number of writers defend Zeeman's embryology paper (Zeeman Lectures on Mathematics in the Life Sciences, 7, 69; 1974). The meaninglessness of this paper's "first-order" quantitative results will be explained in Sussmann \& Zahler Synthese (in the press). Guckenheimer complains that our discussion of evidence is misleading. We printed Zeeman's statement verbatim and then five facts which no one has disputed (with one minor exception; see below). Despite Guckenheimer's attempt somehow to separate confirmation of a model from confirmation of that model's predictions, we feel that most readers will agree that our assessment, and not Zeeman's, is supported by the facts.

Zeeman writes that our article ignores a rigorous version of his main theorem published elsewhere (Zeeman Proc. Int. Cong. Math. Vancouver 2, 533 ; 1974). We criticised the first proof for unjustifiably singling out the timeaxis. The second proof adds an assumption, not mentioned in the paper addressed to biologists, which declares that the time-axis is special-postulating what cannot be proved. Ignoring all the other faults we found in his proof (which are not repaired by the new assumption), Zeeman concentrates his defences on one of our minor criticisms, which concerns the direction of curl of the isolated neural plate. In rebuttal we note that it is Zeeman, not ourselves, who is misquoting Crelin, who clearly states that the graft curls laterally (Crelin J. Exp. Zool. 120, 547; 1952 and private communication); that the mesoderm is too thin to exert the forces Zeeman ascribes to it; and that 'neurulation', the subject of the section containing Zeeman's statement, includes Harrison stage 23, which Crelin studied.

Returning to Prof Guckenheimer's letter: he disagrees with our definition of the word 'catastrophe'; but the definition we use is that used by all the applied catastrophe theorists that Guckenheimer is defending. We agree with Guckenheimer's statement that the confusion of the intuitive notion of jump with the mathematical notion of jump discontinuity is common and useful. What we object to are attempts to switch from one to the other and back in mid-proof. Finally, Guckenheimer complains that our remark about the large number of unrefereed applied catastrophe theory papers is "snide". First of all, it is a fact. Consider, for example, the bibliography prepared by the strong catastrophetheory supporter Lynn Steen in February, 1977 (Steen: Catastrophe Theory: A Selected Bibliography (mimeographed, 1977)). Approximately 70\% of the papers classified there as applied catastrophe theory appear to be unrefereed; we think that this is an unusually high ratio for scientific papers. While no one would say that it is wrong to publish an unrefereed paper, we think it is quite proper to point out this phenomenon, because it indicates that catastrophe theory has grown in an atmosphere largely sheltered from outside criticism, and this partly accounts for its exuberant claims.

RAPHAEL S. ZAHLeR

New Haven, Connecticut

\section{In support of boycotts}

SIR,-Richard Peto and Sir Richard Doll raise an important and difficult issue in their letter about boycotts of congresses to be held in countries controlled by repressive regimes (1 December, page 384 ). As one who lived and worked in South Africa until government action forced me to leave, I can say something about this topic from 'the inside', as it was a subject often discussed by those of us who wished to see change and about which conflicting views were held. I emerged from these discussions as a strong proponent of boycotts for the following reasons (most of which form answers to the points raised by Peto and Doll): - It is often argued that boycotts cause harm to the people one least wishes to harm-opponents of the regime, scientists who need "contact with the international community" or, in the case of economic boycotts, the mass of people of the country (for example, the blacks of South Africa). The fallacy in that argument is that most genuine opponents of repressive regimes will already have been dealt with by the government--imprisoned, silenced by banning, or even murdered. In most countries scientists can, and do keep contact with the rest of the world by travel and are not restricted unless they are actively engaged in politics or openly express opposition to the regime; if they do, they are likely to be dealt with as above. And, in my experience, a majority of politically-aware blacks in South Africa would have accepted the damage that might have resulted from economic sanctions as a necessary and effective means of putting pressure on the government.

- Visits to these countries by prominent people or holding of international congresses is often regarded as tacit acceptance of the regime by the rulers and sometimes exploited as evidence of its acceptability. To opponents of the regime such actions bring a sense of disillusionment and cynicism, and I recall the moral encouragement and gratification one felt whenever a prominent artist, scientist or sportsman announced publicly that he would not visit South Africa.

- Peto and Doll imply that scientists should be "apolitical" as this confers on them a special "useful image", presumably to be used for protests, such as that made by so many scientists against the imprisonment of Mikhail Shtern. The argument may be used with equal force by doctors, sportsmen, artists, businessmen or any other person pursing any other occupation! No group is immune from the responsibility to take a political stance at times, whether this is expressed as a letter of protest or a boycott.

- Boycotts are often said to be ineffective and therefore not worth supporting. This is only true when they are not fully supported. The sporting isolation of South Africa has been most effective and has led to removal of many of the barriers imposed in that country against mixed- 